\title{
Engineering solutions applied to pneumatic drills to reduce losses of dust from dressed seeds
}

\author{
D. Pochi, ${ }^{1}$ M. Biocca, ${ }^{1}$ G. Brannetti, ${ }^{1}$ R. Fanigliulo, ${ }^{1}$ P. Gallo, ${ }^{1}$ R. Grilli, ${ }^{1}$ S. Montanari, ${ }^{1}$ \\ P. Pulcini
}
${ }^{1}$ CRA-ING, Consiglio per la Ricerca e la sperimentazione in Agricoltura, Agricultural Engineering Research Unit, Roma, Italy; ${ }^{2}$ CRA-PAV, Consiglio per la Ricerca e la sperimentazione in Agricoltura, Plant Pathology Research Center, Roma, Italy

\begin{abstract}
Neonicotinoid insecticides (imidacloprid, clothianidin, thiamethoxam) and fipronil for maize (Zea mays L.) seed dressing have been claimed to play a role in honey bee (Apis mellifera L.) decline, since pneumatic precision drills used for sowing contribute to the dispersion of the abrasion dust produced by dressed seeds. The active ingredients (a.i.) can contaminate the environment and can lead to the exposure of operators and bystanders during sowing operations. To achieve a significant reduction of dust drift and to enhance the safety for the operators, CRA-ING studied and developed novel engineering solutions applicable to drills, based on an air-recycling/filtering system. In the first system, the air's excess is forced outward through suitable filters placed on the modified lid of the seed hopper. It can be easily applied to commercial drills in use. The second system was specifically designed for new drills. It consists of a collector duct that receives the air expelled from the vacuum fan opening, creating constant pressure conditions. Part of the air is recycled into the seed hoppers, as the air in excess is directed outward through a single main filter. A third system, based on the second one, entails the use of an electrostatic filter to improve its efficiency. Moreover, to avoid the operator's exposure to the dust during the seed loading, we show an integrated solution based on the use of a modified pre-charged plastic container that replace the drill's hoppers. Preliminary tests ascertained the regular seed distribution with the drills equipped with the prototypes. Then, trials were carried out at fixed point and in field, for detecting the amounts of the drifted a.i., using commercial maize seed dressed with thiamethoxam,
\end{abstract}

Correspondence: Marcello Biocca, CRA-ING, via della Pascolare 16, 00015 Monterotondo, Roma, Italy.

Tel.: +390690675215 - Fax: +390690625591.

E-mail: marcello.biocca@entecra.it

Key words: dust drift, precision seeder, neonicotinoids, dressed maize.

Contributions: the authors contributed equally.

Conflict of interests: the authors declare no potential conflict of interests.

(C) Copyright D. Pochi et al., 2013

Licensee PAGEPress, Italy

Journal of Agricultural Engineering 2013; XLIV(s2):e134

doi:10.4081/jae.2013.s2.e134

This article is distributed under the terms of the Creative Commons Attribution Noncommercial License (by-nc 3.0) which permits any noncommercial use, distribution, and reproduction in any medium, provided the original author(s) and source are credited. imidacloprid, clothianidin and fipronil. The test results show powder and a.i. drift reductions up to a maximum of $94.5 \%$ measured at ground level (with fipronil as a.i.) as a consequence of the use of the prototypes.

\section{Introduction}

The pneumatic precision drills implement a seed distribution system based on vacuum effect created by a centrifugal fan. The sucked air in the circuit of the seeder is finally expelled through the fan opening, dragging with it powder and seed particles that can contain dressing substances. Such as machinery are employed in maize sowing (Zea mays L.) and insecticides employed in maize seed dressing (namely neonicotinoids and fipronil) have been claimed to play a role in honey bee (Apis mellifera L.) mortality and decline (Maini et al., 2010; Apenet, 2011; Tapparo et al., 2012). The situation is particularly serious in Italy, since maize is a major cereal crop, grown on almost one million hectares (Istat, 2011).

In recent years the alarms concerning risks to honey bees have stimulated st udies about technical solutions to reduce dust drift and losses from the drills. Some manufacturers proposed devices, called air deflectors, able to redirect the output flow from the fan exit towards the soil, to reduce the diffusion of dust in the atmosphere. In previous works, tests (carried out on four of the above mentioned insecticides) showed that the adoption of the air deflectors determined a reduction of dust drift at least around $50 \%$ of the active ingredients (a.i.) amounts observed without deflectors at ground level. In the same trials, it was observed a lesser reduction of active ingredient concentrations in the air (Biocca et al., 2011; Pochi et al. 2011a). However it was ascertained that sub-lethal effects to honey bees are still possible with these levels of dust dispersion (Apenet, 2011; Pochi et al. 2012a), and the Italian Government decided the precautionary suspension of use of all the four a.i. registered for seed dressing (i.e. imidacloprid, thiamethoxam, clothianidin and fipronil).

With the aim of obtaining a further drift reduction, a dedicated study initially started in the framework of a national research project funded by the Italian Ministry of Agriculture called Apen et, and innovative devices were developed at CRA-ING. They are based on the partial recirculation of the air operating the seed distribution in traditional pneumatic drills. The air excess is forced outward through suitable filters and expelled.

Moreover, an additional aspect in the risk assessment involves the operators, since they are potentially exposed to abrasion dust during sowing operation s. The exposure can occur differently, such as during the manipulation of dressed seed (opening seed sacks and filling the drill) or in field, during the sowing, at the tractor seat. In order to achieve a higher risk reduction for the operator, we propose an inte- 
grated solution based on the use of a modified pre-charged plastic container that replace the drill's hoppers.

The paper refers about the results of tests carried out in order to assess the performances of the innovative prototypes (with particular reference to the prototype 2, named P2), and shows the employ of the innovative seed conta iner.

\section{Materials and methods}

Seed. The trials were carried out using commercial maize seed (Pioneer Hybreed PR32G44) dressed with four insecticides (Gaucho ${ }^{\mathrm{TM}}$, a.i.: imidacloprid; Poncho ${ }^{\mathrm{TM}}$, a.i.: clothianidin; Cruiser $^{\mathrm{TM}}$, a.i.: thiametoxam, Regent ${ }^{\mathrm{TM}}$, a.i.: fipronil) and a fungicide (Celest ${ }^{\mathrm{TM}}$, a.i.: fludioxonil and metalaxyl). According to the manufacturers, the quantities of a.i. were respectively equal to $1.000 \mathrm{mg} / \mathrm{seed}$ for imidacloprid, 1.250 $\mathrm{mg} / \mathrm{seed}$ for clothianidin, $0.600 \mathrm{mg} / \mathrm{seed}$ for thiametoxam and 0.500 $\mathrm{mg} / \mathrm{seed}$ for fipronil. The seed was packed in sacks (25,000 seeds/sack).

Description of prototypes. The first prototype (P1) is based on a partial recirculation of the air operating the seed distribution in traditional pneumatic drills (Figure 1). The air excess is forced outward through suitable filters placed on the modified lid of the seed hopper. The system is suitable to be easily mounted in commercial drill in use. A first version of this prototype was mounted on a Matermacc drill and tested in 2010 (Pochi et al., 2011b; Pochi et al. 2012b). Then, a similar model of the prototype was mounted on a Gaspardo Magica drill. This prototype was equipped with activated charcoal filters for automotive use.

The second prototype (P2) is a modification of the previous one and is designed for ad-hoc developed drills (Figure 2). It consist of a collector duct that receives the air expelled from the vacuum fan opening, creating constant pressure conditions. Part of the air is recycled into the seed hoppers, as the air in excess is directed outward through a single main activated charcoal filter. The prototype was mounted on a Gaspardo Magica, six-rows drill.

Sowing quality assessment. In preliminary tests it was ascertained the regular seed distribution in the drills equipped with the prototypes by means of tests carried out at fixed point (P1) or directly during field sowing (P2); in field the quality of sowing was evaluated according to standard Enama (2003).
Test system (fixed point). The tests were carried out in the workshop's porch of CRA-ING, according to the settings described in Biocca et al. (2011). The drill, suitably placed in the test area, operated the seed distribution "sur place". In the test site artificial wind conditions were produced by means of an axial fan ( $0.735 \mathrm{~m}$ diameter), to obtain a sort of wind gallery with a $22.5 \mathrm{~m}$ long sampling area, leeward with respect to the drill position. Along the sampling area a grid of 15 sampling points with Petri dishes (filled with an acetonitrile-water solution) was arranged. The five sampling distances from the drill side were multiples of its working width: 4.5, 9.0, 13.5, 18 and $22.5 \mathrm{~m}$. In the sampling area, five air samplers (TCR Tecora model "Bravo") were set for sucking $100 \mathrm{~L}$ of air with a constant flow of $5 \mathrm{~L} \bullet \mathrm{min}^{-1}$, in order to complete the air sampling $5 \mathrm{~min}$ after the end of the seed distribution. Each trial was replicated three times. Each replication consisted of the distribution of 2 sacks of seed, corresponding to a 0.67 ha surface. The drill operated the seed distribution by means of a system allowing to adjust the peripheral speed of the drill's driving wheel. Such a system consisted of an electric engine connected to the driving wheel through a gear-reducer (transmission ratio: 40/1). An inverter (OMRON Varispeed V7) was installed to set the speed of the driving wheel, on the desired value of $1.67 \mathrm{~m} \mathrm{~s}^{-1}$. The drill was regulated as follows: row distance of $0.75 \mathrm{~m}$; seed distance on the row of $0.18 \mathrm{~m}$; sowing density of 75,000 seeds ha $^{-1}$; vacuum pressure of 45 mbar.

Field test. The trials were carried out in the experimental farm of CRA-ING (around 42 ${ }^{\circ} 5^{\prime} 51.26^{\prime \prime} \mathrm{N}$; 12 $2^{\circ} 37^{\prime} 3.52^{\prime \prime} \mathrm{E}$; $24 \mathrm{~m}$ a.s.l.) in 2011 and in the experimental farm of CRA-PCM in 2012 (around 12 $477^{\prime} 46^{\prime \prime} \mathrm{E}$; $42^{\circ} 26^{\prime} 50^{\prime \prime} \mathrm{N}$; $370 \mathrm{~m}$ a.s.l.), sowing plots of about 3 ha with all the four a.i.

To detect the a.i. air concentrations, a personal sampler, operating at a constant flow of $4.0 \mathrm{~L} \mathrm{~min}^{-1}$ was placed on the tractor cab.

Moreover, during the tests four air samplers (TCR Tecora, mod. Bravo) were used to collect samples of the powder present in the ambient air. The air sampling heights were $2.0 \mathrm{~m}$ and $5.0 \mathrm{~m}$. A couple of samplers were placed at the edge of the field. Considering the prevailing wind direction at the beginning of the trial they were placed leeward. The second couple of samplers were placed in the centre of the sowed field. The pumps of all ambient samplers were calibrated with a constant flow of $15 \mathrm{~L} \mathrm{~min}^{-1}$. All the portable samplers were equipped with $0.45 \mathrm{~m}$ PTFE Millipore diskette filters, without any sampling head. During the tests, the micrometeorological conditions were monitored.

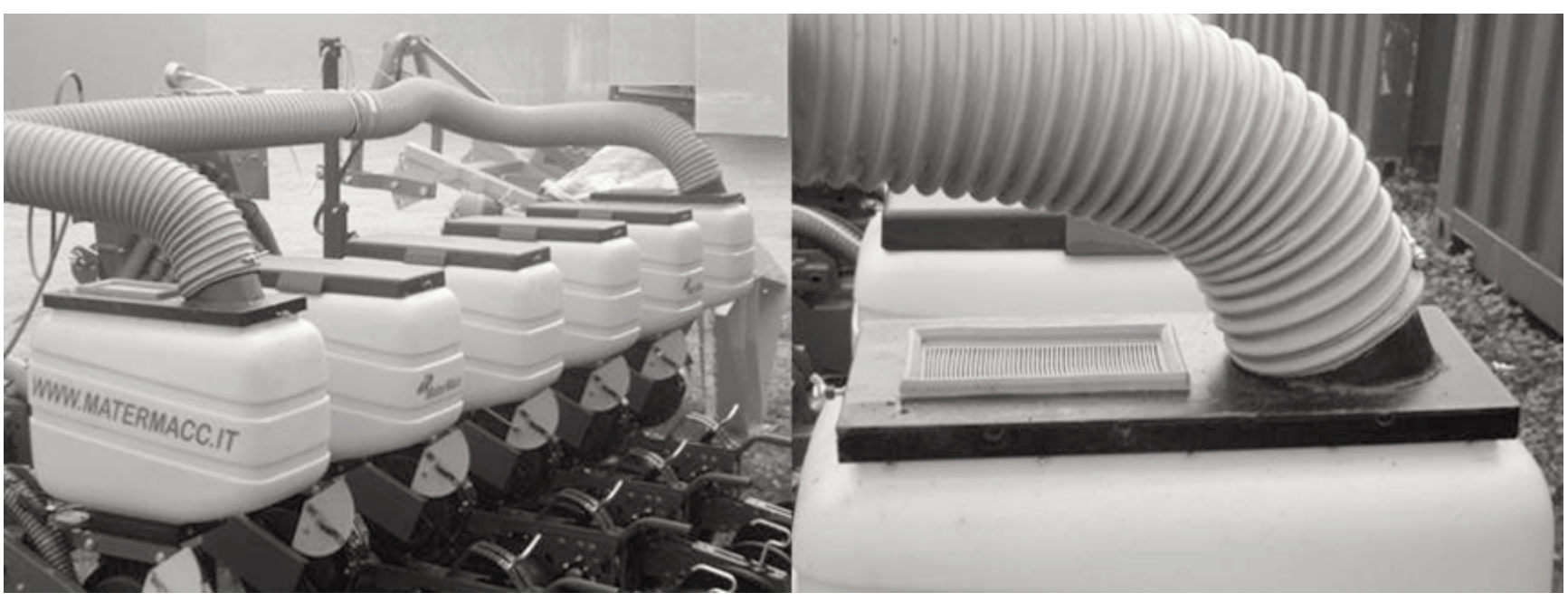

Figure 1. The prototype 1 applied to a Matermacc drill. 


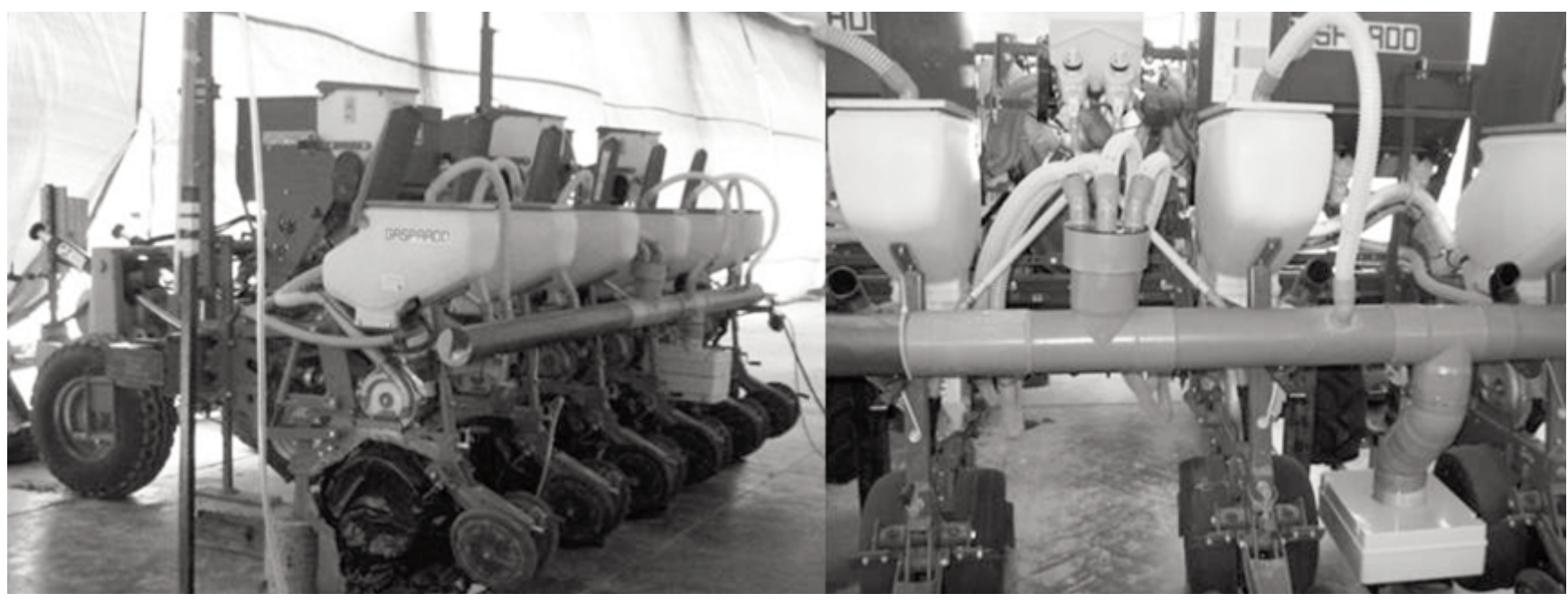

Figure 2. The Gaspardo drill equipped with the prototype 2.

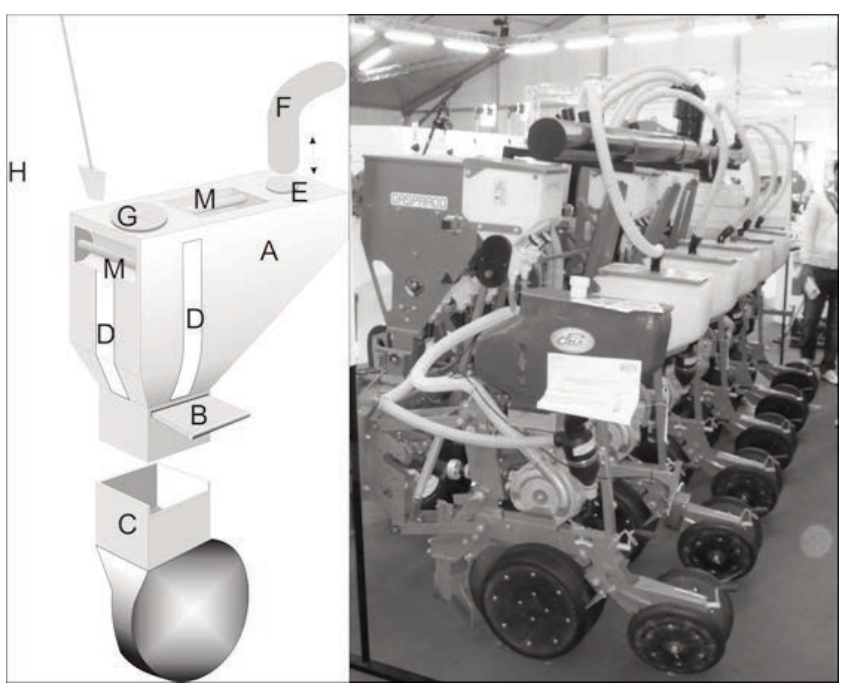

Figure 3. The innovative hopper. Left: layout. Right: mounted on the drill.

Active ingredients determination. The active ingredient determination in the filters was made at CRA-PAV. Active substances were extracted from the samples with acetonitrile. Solutions were sonicated in an ultrasonic bath for $10 \mathrm{~min}$, then filtered with HPLC $0.45 \mathrm{~m}$ filters. The analytical determinations were carried out by means of HPLC - ESI - MS - MS and the relative methods were validated in compliance with GLP procedures (Biocca et al. 2011).

Innovative seed container. An innovative hopper was designed and a prototype was built in fibreglass. It consists of containers that can be indefinitely refilled and reused, replacing the conventional hoppers. The introduction of such refill-hoppers involves a modification of the process from the packaging to the sowing. They are filled and sealed in the seed production plant, where all the operations that causing the production and dispersion of dust (with a.i,) can be made under controlled conditions. Each refill-hopper represent a dose of seed. The farmer purchases the number of doses he needs and after the sowing returns the empty hoppers to the plant where they will be prepared for the next season. As to their use, the farmer only must place them on the seed distributor and pull out the closure latch, allowing the seed to fall in the distributor. Then the container was mounted on the Gaspardo drill and checked for its functionality (Figure 3).

\section{Results}

The quality of seed distributions of the drill equipped with the prototypes resulted always acceptable, showing the same homogeneity of the sowing carried out with the drill without modifications (Pochi et al. $2012 \mathrm{~b})$.

The Figure 3 shows the residues of a.i. collected in Petri dishes in the tests at fixed point. The amounts (expressed as $\mu \mathrm{g} \mathrm{m}^{-2}$ ) appear very large as they represent the total dust potentially emitted during the sowing of an area of 0.67 ha. As expected, the quantities of a.i. residues at ground level decrease with respect to the distance from the emission source.

On the other hand, the air concentrations of a.i. in the sampling area appears less linked to the distance (Figure 4). The phenomenon can be

Table 1. Air concentrations of active ingredients recorded during sowing with the prototype (P2) and the conventional drill.

\begin{tabular}{lcccc}
$\begin{array}{l}\text { Sampler } \\
\text { position }\end{array}$ & $\begin{array}{c}\text { Sampling } \\
\text { (n) }\end{array}$ & a.i & $\begin{array}{c}\text { P2 } \\
\text { ppb }\end{array}$ & $\begin{array}{c}\text { Conventional } \\
\text { ppb }\end{array}$ \\
field & 4 & clothianidin & 0.012 & 0.223 \\
& 4 & fipronil & 0.008 & 0.057 \\
\hline & 4 & imidacloprid & 0.011 & 0.025 \\
& 4 & thiamethoxam & 0.009 & 0.036 \\
\hline & 1 & clothianidin & 0.563 & 0.236 \\
\hline & 1 & fipronil & 0.087 & 1.427 \\
\hline & 1 & imidacloprid & 0.129 & 0.976 \\
\hline
\end{tabular}




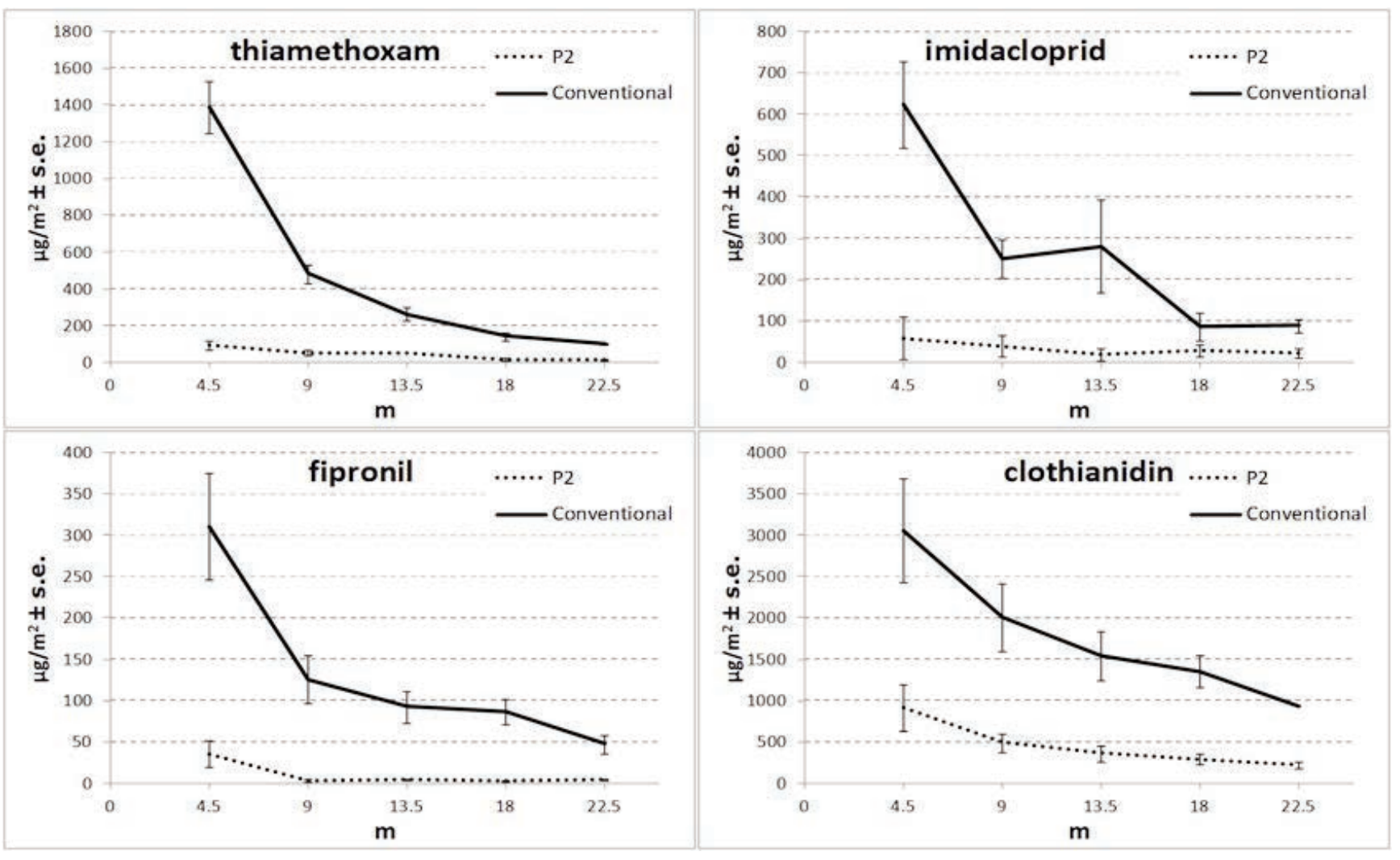

Figure 4. Ground depositions $\left[\mu \mathrm{g} \mathrm{m}^{-2} \pm\right.$ s.e.] obtained comparing prototype 2 and conventional drill in fixed point tests.

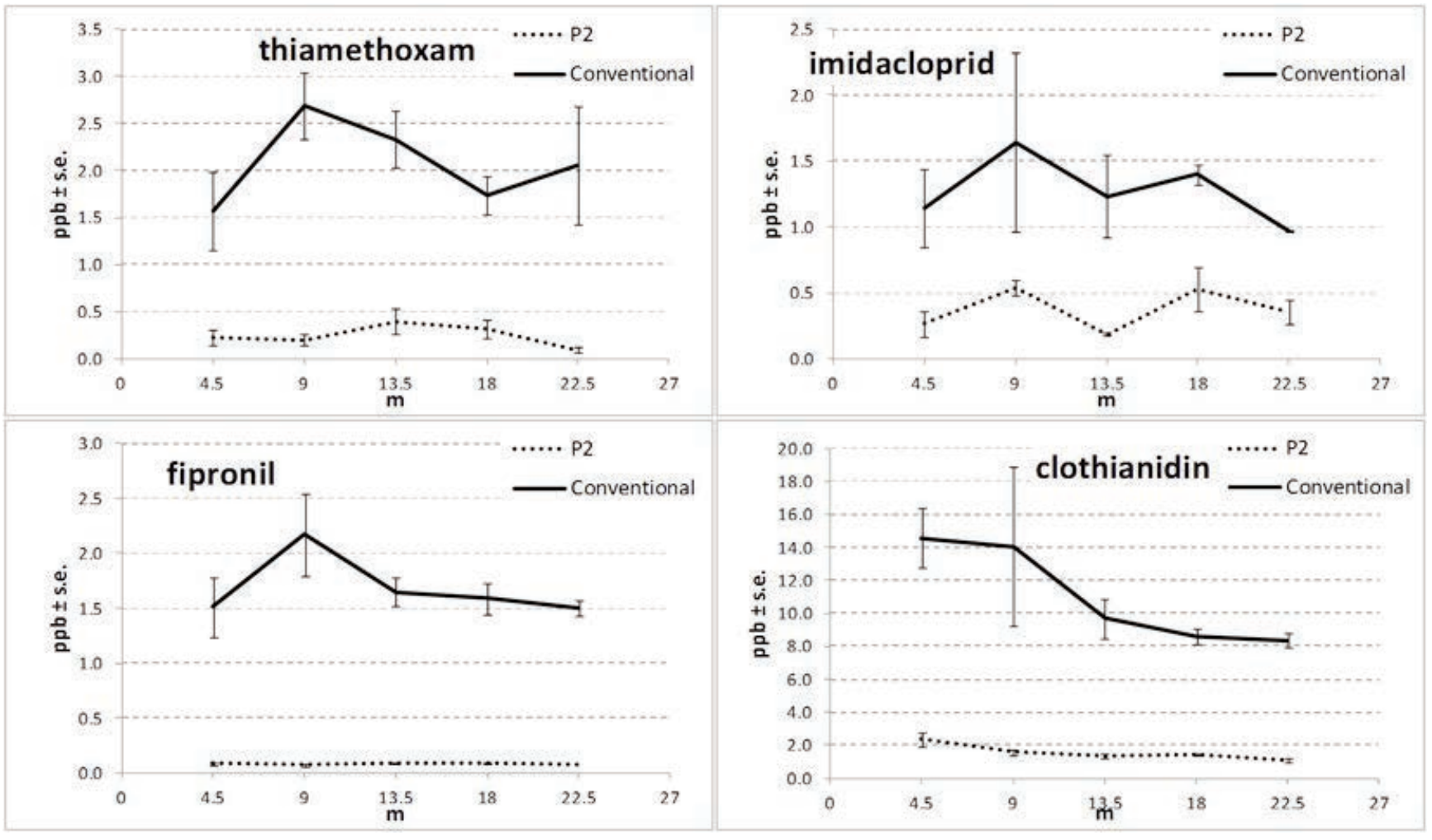

Figure 5. Air concentrations [ppb \pm s.e.] obtained comparing prototype 2 and conventional drill in fixed point tests.. 
related to the presence of very fine particles that can float in the air for long time.

As to the field tests, we sampled the air concentrations of a.i. during the entire sowing of plots of about three hectares. The Table 1 shows the results, as average values of concentrations detected by the four samplers placed in the field (two samplers at the field edge and two samplers in the center of the sowed plot) and the amounts detected by the samplers mounted on the tractor during the sowing. Minor concentrations were always observed with the employ of the prototype, except for the sampling of clothianidin with the sampler placed on the tractor.

In general, in the experiments at fixed point, the drift reduction incited by the prototype is very clear, both at ground level and in the air, ranging from a minimum of about $71 \%$ (case of imidacloprid as air concentration) to a maximum of about $95 \%$ (case of fipronil as air concentration) (Table 2). Very similar results were also achieved in field measuring the air concentrations into and near the sowed plot. In the case of the sampling on the tractor, it appears that in one case (clothianidin) an increment in the dust drift with the prototype was observed. Such an exception, considering the general significant reduction determined by the use of the prototype, could have been caused by some abnormal event such as contamination of the samples.

Regarding the study of an innovative method to load the drill avoiding the dispersion of dust during the hopper filling, we developed a system based on airtight hoppers used both for the packaging and seed filling. A fiber-glass prototype of such hoppers was realized at CRA-ING and is shown in fig. 3. The introduction of the refill hoppers and of the process related to their utilization completely eliminates the workers exposition to the dust during the seed loading and, in general, reduces the overall risks for the environment. Moreover, because of their indefinite reutilization, the conventional packages are no more requested, saving the cost for their purchasing and avoiding the problem of their disposal as hazardous wastes. The refill hopper can be easily applied to seed drills in use with simple adaptations of the upper opening of the seed distributors in order to lodge them. Further advantages and increased efficiency of the process could be achieved through agreements among the potential stake-holders (seed producers, drills manufacturers, etc.) about the adoption of standard shapes and dimensions of the technical elements, facilitating their diffusion. Similar process could be advantageously adopted in other fields of application in which the manipulation of granular or powder products represent a potential risks for the operators.

\section{Conclusions}

This paper shows concentrations of the a.i. emitted by drills equipped with innovative systems developed at CRA-ING. The data are expressed in terms of residue concentrations both in the air and at

Table 2. Relative reductions of a.i. emissions incited by prototype 2, with reference to the conventional drill.

\begin{tabular}{lccc} 
Active & \multicolumn{2}{c}{ Fixed point } & Field \\
ingredient & Ground [\%] & Air [\%] & Air [\%] \\
fipronil & 92.1 & 95.0 & $93.6 \%$ \\
thiamethoxam & 90.6 & 88.2 & $98.6 \%$ \\
\hline clothiadinin & 74.4 & 86.0 & $-25.3 \%$ \\
imidacloprid & 87.4 & 70.7 & $86.0 \%$ \\
\hline
\end{tabular}

ground level. Starting from these results, the relative reduction of emission incited by the prototype, was expressed as percentage with reference to a conventional drill. In other terms the comparison of the drill performance were based on real data of a.i. contents.

The results show a remarkable reduction of drift and the efficacy of the innovative systems. The systems were applied to commercial drills without interferences with the quality of seed deposition. The effect of reduction of dust emission incited by the innovative systems was always higher than the one caused by other drift reducing devices (air deflectors) previously tested (Biocca et al., 2011; Pochi et al., 2011a). Nevertheless even with the strongest reductions of dust drift, some undesirable effects for honey bees may occur during their flight in and around contaminated areas due to the high sensitivity of these insects to neonicotinoids and fipronil (Pochi et al., 2012). Consequently, further studies are needed, aimed at providing engineering solutions on the machineries to obtain a better control of dust drift.

\section{References}

Apenet, 2011. Effects of coated maize seed on bees. Report based on results obtained from the first year of activity of the APENET project. Pag 131. Available at: http:/www.reterurale.it/flex/cm/pages/ ServeBLOB.php/L/TT/IDPagina/1289. Accessed: April 10th, 2012.

Biocca, M., Conte, E., Pulcini, P., Marinelli, E. and Pochi, D., 2011. Sowing simulation tests of a pneumatic drill equipped with systems aimed at reducing the emission of abrasion dust from maize dressed seed. Journal of Environmental Science and Health, Part B. 46, 6, 438-448.

ENAMA, 2003. "Protocollo Enama Cat. 04 - Macchine per la semina" (Rev. 2.1 settembre 2003).

ISTAT, 2011. Tavole di dati. On line: http://agri.istat.it. Accessed February 2013.

Maini, S., Medrzycki, P. and Porrini, C., 2010. The puzzle of bee losses: a brief review. Bull Insectology 63, 1, 153-160.

Pochi, D., Biocca, M., Fanigliulo, R., Conte, E. and Pulcini, P., 2011 a. Evaluation of insecticides losses from dressed seed from conventional and modified pneumatic drills for maize. Journal of Agricultural Machinery Science, 7, 1, 61-65.

Pochi, D., Biocca, M., Fanigliulo, R., Gallo, P., Pulcini, P. and Conte, E., 2011b. An innovative system to reduce dust drift during sowing of dressed seeds with pneumatic drills. Proceedings of XIV Symposium in Pesticide Chemistry, Piacenza (Italy) 30th August 1 st September 2011.

Pochi D., Biocca M., Fanigliulo R., Pulcini P. and Conte E., 2012a. Potential exposure of bees, Apis mellifera L., to particulate matter and pesticides derived from seed dressing during maize sowing. Bulletin of Environmental Contamination and Toxicology. DOI: 10.1007/s00128-012-0664-1.

Pochi D., Biocca M., Fanigliulo R., Gallo P. and Pulcini P., 2012b. Development and testing of innovative devices to reduce the drift of abrasion powder during the sowing of dressed seeds with pneumatic drills. In: International Conference of Agricultural Engineering, CIGR-AgEng 2012, Valencia 8-12 July. ISBN -10: 84 615-9928-4. On-line at: http://cigr.ageng2012.org.

Tapparo, A., Marton, D., Giorio, C., Zanella, A., Soldà, L., Marzaro, M., Vivan, L. and Girolami, V., 2012. Assessment of the environmental exposure of honeybees to particulate matter containing neonicotinoid insecticides coming from corn coated seeds. Environmental Science and Technology, 46,5, 2592-2599. 